\title{
Training seafarers to deal with multicultural crew members and stress on board
}

\author{
Hans-Joachim Jensen ${ }^{1,2}$, Marcus Oldenburg ${ }^{2}$ \\ ${ }^{1}$ Flensburg University of Applied Sciences, Germany \\ ${ }^{2}$ Institute for Occupational and Maritime Medicine Hamburg (ZfAM), University Medical Centre Hamburg-Eppendorf (UKE), Germany
}

\begin{abstract}
Background: The present study describes the intercultural differences in the perception of stress and the preparation of seafarers.

Materials and methods: Three hundred twenty-three seafarers (156 [48.3\%] Europeans and 167 [51.7\%] Southeast Asians) were interviewed about their subjective stress on board.

Results: According to the interviews with ship's officers, mostly represented by Europeans, mental stress was most often due to high responsibilities (82.0\%), extensive administrative tasks (81.1\%) and lack of qualification of seafarers (64.8\%). Subjectively, the Europeans questioned were significantly more likely to experience mental stress on board than the Southeast Asians ( $74.2 \%$ vs. $56.3 \%)$, whereas the latter were more prone to being physically stressed. $43.1 \%$ of the Southeast Asian seafarers often felt lonely on board compared with $26.2 \%$ of the Europeans. Preparation for maritime-specific stress in the form of specific training units is only provided in 1 of the 5 universities surveyed. The most important reason for this is a lack of time. Intercultural leadership training was also only offered at one university.

Conclusions: In view of the many psychophysical stressors in daily life on a ship and the lacking respective education, it is recommended to integrate stress management and diversity training in intercultural communication in the higher education of future superiors on board.
\end{abstract}

(Int Marit Health 2020; 71, 3: 174-180)

Key words: cultural differences, maritime, stress, training, seafarer

\section{INTRODUCTION}

According to Salomon (2019) [1], mental stress is defined as mental excitement caused by mental demands. In the maritime context, this means, for example, high attention during watch keeping, high responsibility in the management of the ship. On the other hand, physical stress is associated with physical exertion and being active beyond capacity [2] (in seafaring, for instance, through hard physical work, lashing, or ship movements). A high level of chronic physical stress can lead to severe physical exhaustion and complaints regarding the musculoskeletal system $[1,2]$.

For Forsell et al. [3], psychosocial stress is the most frequent problem in the workplace on merchant vessels, apart from noise, vibration and the risk of accidents. This is also confirmed in the study by Nielsen et al. [4], who observed that physical and psychosocial work factors are important reasons for job dissatisfaction and fluctuation. In connection with mental stress and mental health of seafarers, Iversen [5] found an increased rate of depression and suicide among seafarers.

Occupational stress factors, such as a lack of separation between work and leisure, are practically an essential feature of the seafaring profession. Seafarers normally spend longer periods of time on board, leisure activities take place in the same environment and the crews are subject to continuous physical stress impacts through vibration, noise and ship movements [6]. For this reason the crew members' everyday life is still subject to high levels of mental and psychosocial stress [7-9]. This also reduces the recreational value for seafarers during their leisure time.

Within the past decades, stress situations, such as long, irregular working hours and, in particular, isolation and con- 
flicts between crew members have increased in seafaring [10]. Furthermore, growing rationalisation measures [11] often complicate the everyday work on board. These developments require a tailor-made preparation of prospective ship's officers in nautical training. Shipping companies and in particular maritime stakeholders are responsible for the appropriate training of shipping crews. Jeżewska et al. [12] and Carotenuto et al. [7] also recommend the development of shipboard "strategies for coping with inevitable stress conditions".

The appropriate preparation of the superiors in their maritime training is enshrined in the International Safety Management (ISM) Code of the International Maritime Organisation (IMO) [13]. One objective of the ISM Code is to protect people from harm to life and limb. In addition, the IMO has an International Convention on Standards of Training, Certification and Watchkeeping for Seafarers (STCW, 1995) [14], which define internationally comparable standards in the training of seafarers. The Convention also includes medical-psychological training procedures for ship's personnel and is internationally binding. Thus, the nautical students should already receive basic medical-psychological training during their university education. In addition, the future leaders on board should be briefed on how to provide first-aid during a potential medical emergency on the high seas far from professional support.

Nowadays, merchant ships are multinationally manned with a high proportion of Southeast Asian crew members [15]. The linguistic or cultural differences among the employees on board can lead to significant understanding problems. Particularly Asian crew members with their strong family ties and their intense needs for contact often feel mentally stressed due to the lack of social relations on the high seas [16, 17]. In addition, especially Southeast Asians, who are usually deployed as ratings, are often exposed to high levels of physical stress in daily life on board (e.g. during loading) [18]. Overall, seafarers' cultural background should be taken into account when assessing their psychophysical stress by examining their working situation. Consequently, further requirements also arise for prospective ship's officers to lead crew members with different cultural backgrounds [19].

The present study addresses the issue of psychological stress for crew members, possible cultural differences in the experience of stress, and the particular stress and strain experienced by ship's officers. A further question that arises from this is the extent to which prospective ship's officers are prepared in their training for mental stress and the management of multicultural crews with their particular work situation. For example, Youssuf [20] postulated measures to combat stress in maritime shipping as seafarers are exposed to particular psychological stressors such as family separation, loneliness, limited recreational opportunities or lack of sleep.

Furthermore, as a higher proportion of East Asian crew members, mainly Filipinos, experiences the work situation and the social relations on board as stressful - compared to European seafarers $[16,17]$ - the training of nautical officers should also encompass the responsibility and the need of qualification for the ship's officers in the leadership of multicultural crew members. The motivation of crew members mentioned in the ISM Code as well as possible communication problems due to linguistic and cultural differences also seem to require training of the superiors on board in intercultural communication and leadership.

In Germany, nautical education is provided at 5 Universities of Applied Sciences in Flensburg, Elsfleth, Bremen, Leer and Wismar over 6 semesters and includes navigation, cargo technology, telecommunications, emergency management and law. However, no data is available on the training of prospective ship's officers in stress management and on intercultural communication and leadership training. Therefore, this study presents and discusses the intercultural differences in the subjective perception of stress and the preparation of seafarers, in particular of superiors, for ship-specific stressors and intercultural leadership in higher education.

\section{MATERIALS AND METHODS}

An own recent literature review has shown that standardised maritime methods are not available for stress analysis that covers the special working and living conditions in seafaring (data not published). Leszczyńska et al. (2008) [21] also stated that such suitable and standardised methods are lacking in seafaring. For this reason, the interview method was selected in this study as a qualitative research method. The interview was developed on the basis of the most important shipboard stressors (according to a previous maritime specific stress survey of seafarers [9]), as well as on the results of several previous qualitative interviews with seafarers, officers and ratings.

The interview questions were related to the specific working conditions for officers and ratings in ship operation and allowed a bivariate response behaviour (stressful or not). The questionnaire used for the officers consisted of five questions about their specific workload with regard to high responsibility, extensive administrative work, lack of qualification of seafarers, conflicts between security and economy and frequent difficulties with staff on land during port handling. To assess the subjective stress, the following items were asked in the whole study population: mental or physical stress, irregular working times, loneliness, vibration, noise, ship's movements, acclimatising to a new ship, relationships with superiors and understanding of problems. 
The standardised interview guide was tested and optimised in pilot studies both on board a container ship and within a sample of 200 seafarers. The interviewer on board had maritime and scientific qualifications and interview experience (see quality aspects). The survey by an interviewer usually enables an immediate completeness check and the elimination of ambiguities as a quality criterion [22].

The interview procedure was examined according to the quality aspects of an interview [23, 24]. Quality aspects are conceptual quality, structural quality, process quality and result quality. The conceptual quality is determined by a meaningful, unambiguous question and an appropriate context such as the consideration of the interviewees' language skills. The present study is based on a clear question. The developed guideline interview was checked in a pre-test with seafarers with regard to linguistic and content-related comprehensibility, relevance to the specific professional conditions of ocean shipping and an acceptable survey time in a four-eye interview procedure. The structural quality refers to the qualification of the investigators to carry out an interview competently, as well as the organisational framework such as rooms for individual interviews. In the present study, the interviewer was an educational scientist with a maritime profession and practical interview experience. A single cabin was available on each examination ship for a four-eye interview. Process quality is about the concrete implementation of the interview, such as minimum participation of the interviewees through informed consent, compliance with ethical standards, data protection and appropriate feedback. The quality of results refers to the relevance of the results for the solution of the respective practical problem. The interview results of the present study are the basis for further processing of the question. They serve as a possible justification for the necessary psychological preparation or training of prospective ship's officers for the specific personnel and stressful situation of ship operation.

The investigation was conducted during 22 sea voyages (aboard 16 small container ships in the exclusive coastal voyage and 6 large container ships with worldwide shipping routes). In this study, a total of 323 seafarers were interviewed about their psychophysical stress on board (participation rate $88.5 \%$ ). All seafarers were male. 234 participants were married (72.4\%) and 217 (67.2\%) had children. The study sample consisted of 156 Middle and East Europeans (48.3\%) and 167 Southeast Asians (51.7\%; mostly Philippines). In addition the participants were grouped in 122 (37.8\%) officers and 201 (62.2\%) ratings. The average age of crew was $38.2 \pm 11.8$ years with no differences in age between the two cultural groups or the ranks.
Participation in the study was completely voluntary and the data collected was pseudonymised. All participants gave their written informed consent before taking part in this study. The study was approved by the Ethics Committee of the (blinded) Hamburg Medical Association (no. PV4395).

Furthermore, a psychologist and a physician conducted interviews at all 5 German universities with maritime training courses and evaluated their curricula. The interviews in the universities dealt with the question of whether the students, as future ship's officers, would be prepared for dealing and coping with mental stress situations in ship operation and the leadership of multi-ethnic seafarers. It was important to find out the reasons and attitudes if such preparation and training did not take place and whether a corresponding training concept is planned for the future. Interview partners were twice the Deans of the Faculties, once the President of the University and 4 times the Professors for Nautics or Ship Operation Engineering.

All interviews were also based on an interview guideline in a semi-standardised process. During the development of the interview guideline, a flexible set of questions was compiled. The evaluation was qualitatively based on the coding procedure of Kvale and Brinkmann [25]; through coding, a text passage or records could be transformed to an interview code, i.e. keywords or terms. In a synopsis, the results of the interviews were compiled separately by the two scientists and finally supplemented and compared with each other. The two interviewers had an overall agreement of more than $95 \%$. In cases of discrepancies, an agreement was found after discussion.

\section{STATISTICAL ANALYSIS}

Data analysis was performed with SPSS for Windows (version 25.0, SPSS GmbH Software, Munich, Germany). Continuous variables were presented as mean \pm standard deviation (SD). The Pearson $\chi^{2}$ test was applied to compare frequencies between groups. All indicated $p$-values were two-sided, and a $\mathrm{p}$-value of $<0.05$ was regarded as statistically significant.

\section{RESULTS}

\section{PSYCHOPHYSICAL STRESS OF SEAFARERS}

In the context of ship management, psychophysical stress among officers was most often caused by high responsibility $(82.0 \%)$ and extensive administrative work (81.1\%). Other relevant stress factors for officers were, in decreasing order, the lack of qualification of subordinate crew members irrespective of their nationality (64.8\%), conflicts between security and economy (59.8\%) and frequent 
Table 1. Subjective stress of officers during job performance

\begin{tabular}{lcccc}
\hline & All officers (122) & $<\mathbf{4 0}$ years (59) & $\mathbf{2 ~ 4 0 ~ y e a r s ~ ( 6 3 ) ~}$ & P $\boldsymbol{\chi}^{\mathbf{2}}$-test) \\
\hline High responsibility & $100(82.0 \%)$ & $48(81.4 \%)$ & $52(82.5 \%)$ & 0.865 \\
Extensive administrative work & $99(81.1 \%)$ & $48(81.4 \%)$ & $51(81.0 \%)$ & 0.955 \\
Lack of qualification of seafarers & $79(64.8 \%)$ & $35(59.3 \%)$ & $44(69.8 \%)$ & 0.224 \\
Conflicts between security and economy & $73(59.8 \%)$ & $32(54.2 \%)$ & $41(65.1 \%)$ & 0.222 \\
Difficulties with staff on land during port handling & $71(58.2 \%)$ & $33(55.9 \%)$ & $38(60.3 \%)$ & 0.624
\end{tabular}

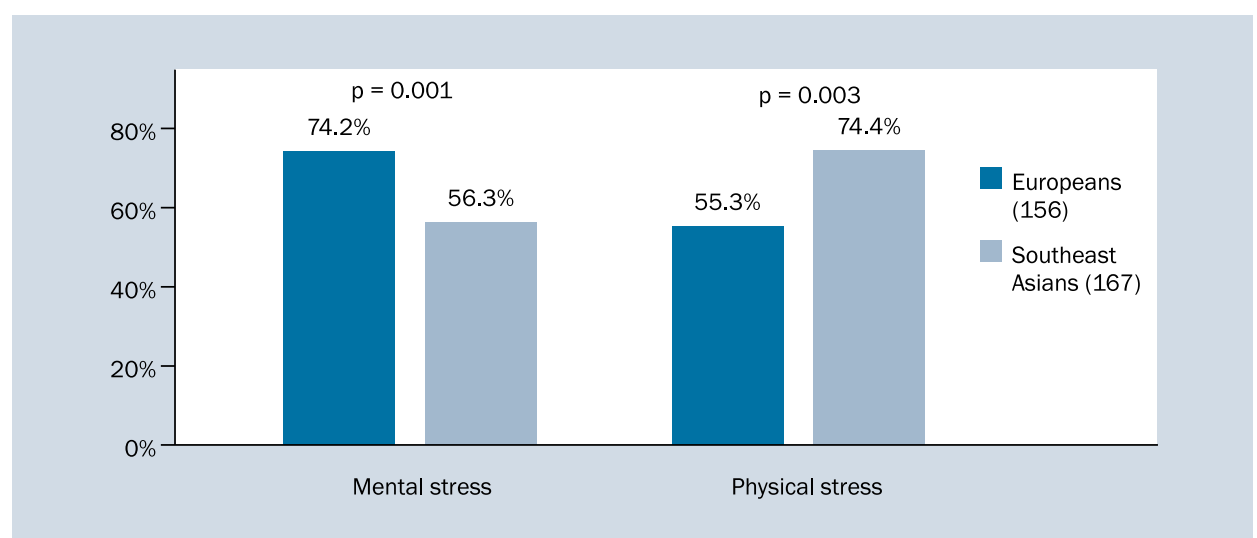

Figure 1. Cultural differences in seafarers' stress $\left(\chi^{2}\right.$-test)

difficulties with staff on land during port handling (58.2\%). Considering the age of the officers, there were no significant differences in the frequency of subjective stress concerning the mentioned management duties (Table 1).

For the ratings, physical strain (72.4\%) was in the foreground. Europeans were significantly more likely to experience mental stress on board than Southeast Asians (74.2\% vs. $56.3 \%$ ). The latter, on the other hand, experienced physical demands significantly more frequently in their daily routine on board ( $74.4 \%$ vs. $55.3 \%$ of Europeans, Fig. 1). After adjusting for age, the described associations remained significant.

In particular, the irregular working hours were more often stressful for European crew members compared to Southeast Asian seafarers (87.2\% vs. $71.8 \%, p=0.02) .43 .1 \%$ of the Southeast Asian participants often felt lonely on board compared with $26.2 \%$ of Europeans ( $p=0.002)$. One in four Southeast Asian crew members (24.0\%) more often stated being "sad and depressed" on board (Europeans 10.3\%; $p=0.001$ ). No differences were observed between the ethnic groups regarding subjective mental stress due to vibration, noise and the ship's movements.

More than half of the Southeast Asian seafarers (53.9\%) and $44.2 \%$ of the Europeans had difficulties acclimatising to a new ship. In terms of their relationship with the supervisor on board, $37.1 \%$ of the Southeast Asians and $23.7 \%$ of the Europeans believed that the supervisors usually did not understand the problems of their subordinate crew members $(p=0.033)$.

\section{INTERVIEWS WITH THE UNIVERSITIES CONCERNING TRAINING IN STRESS MANAGEMENT}

According to the interviews with the university representatives, preparation for maritime-specific stress in the form of specific training units is only provided in 1 of the 5 universities surveyed. Although appropriate training was considered useful by all university representatives, 4 of them had not thought about the possibilities of including special training to prepare the students for occupational stress on board. The most important reason for this is a lack of time. For most of them, the compulsory portion of the STCW is "so large and so packed" that training to reduce stress (for example, anti-fatigue training), even within compulsory or optional subjects, is not possible. According to the statement of one interview partner, a university was not suitable for such a training concept due to its traditional tuition style in seminars, according to which the training of maritime students consists of three stages: board practice, study at the university and initial experience as a ship's officer under guidance. Thus, university education only covers one third of the training for ship's officers. According to 4 representatives, such training in stress management is rather the responsibility of shipping companies. 


\section{INTERVIEWS WITH THE UNIVERSITIES CONCERNING TRAINING IN INTERCULTURAL COMMUNICATION AND LEADERSHIP}

In respect of intercultural leadership training, the interview results in the universities show that this training is only treated more comprehensively in a maritime psychology and personnel management module in one university. In one other university, these training contents are superficially integrated into other subjects such as health care or ship simulation exercises. For three universities, such training is not feasible for time reasons. Nevertheless, one of these three universities is thinking of introducing intercultural communication training. Furthermore, the other two universities without such training see the necessity to teach intercultural leadership competence to the students. However, this content should then be binding in the compulsory curriculum according to STCW.

\section{DISCUSSION}

Considering that in a socio-centred culture, such as that from which the East Asian crew members come, close social ties, group orientation, community affiliation, and collective identities are meaningful, particularly strong psychosocial stress is suspected within the Southeast Asian crew members on board [26-28]. This could also explain why Southeast Asian crew members more often subjectively felt "lonely" or "sad and depressed" on board. The predominance of these findings among South-Asian seafarers is also likely due to their long-lasting time spent away from family, which is usually considerably longer than among European seafarers.

In the recent and relatively comprehensive study about "Seafarers' mental health and wellbeing" by Sampson and Ellis [29], seafarers more often reported isolation and loneliness at sea. Every fifth seaman (20\%) described themselves to be always or very often alone. The authors found evidence of emotional exhaustion, burnout and an evidence of an "increase in anxiety and depression among serving seafarers". The latter often feel down by discrimination, having a "bossy captain", conflicts with superiors and other crew members. The authors evaluated the results of the study as need to improve the psychological conditions for the seafarers on board.

More than a third of the Southeast Asian crew believed that the supervisors did not understand the problems of their subordinate crew members. The socio-centric orientation of seafarers from East Asian cultures also has an influence on their understanding of leadership. These crew members expect respect and understanding for their personal problems and situations in return for their personal commitment, their loyalty to their supervisor and compliance with their orders.
The high level of psychosocial stress in the multicultural context on board, the critical attitude of several crew members towards the superiors' behaviour as well as the requirements of the ISM Code necessitate a corresponding qualification of the ship's officers in intercultural communication and personnel management. Seafaring-related diversity training is a suitable method for imparting these competences. Diversity training programmes are not only conducted traditionally in the business world, but also in other occupational groups such as health and care [30, 31]. According to Theotokas et al. [32], cultural diversity in maritime shipping requires appropriate training and further education for more effective communication between seafarers and managers. In particular, maritime diversity training should include attitudinal and behavioural content and should be action-oriented. Moreover, this training should take into account the different professional experience and the ethnicity of workers [33]. Training in cultural diversity enables the identification of psychosocial needs of multi-ethnic seafarers and can improve well-being. According to the findings of Smith et al. [34], social support and recognition by superiors can improve communication and relationships in the psychosocial working environment of multi-ethnic working groups.

In light of the abundance of ship-specific stressors, training in stress management (especially short-term relaxation methods such as breathing techniques and power napping) for seafarers seems very useful. The meta-analysis of Kröll et al. [35] distinguishes between three forms of stress management training: cognitive-behavioural skills training, relaxation techniques, and multiple stress management training. These different kinds of stress management training can improve employees' psychological health [36].

A "Multimodal Stress Management Training" programme combines a cognitive management component with a change of attitudes and the evaluation of stress situations, on the one hand, and a palliative-regenerative part with the reduction and control of psychophysical stress reactions on the other hand [37]. In addition to a change in attitude and assessment in cognitive stress management, palliative-regenerative stress management is particularly suitable for short-term relaxation, which, given the specific conditions of a ship's operation with its long and irregular working hours, is very helpful for regeneration [38]. Umanodan et al. [39] also suggest a multi-component stress management programme. According to their results, it is effective in improving knowledge and the professional effectiveness of worksite stress management [36].

The maritime education at the respective universities in Germany and thus also possible stress management training are aligned with the needs of German and, at most, other Central European students. According to the inter- 
views performed, it can be concluded that the hypothesis of the studies was confirmed, i.e. that training concerning stress management and intercultural communication and leadership is not sufficiently dealt with in current education. Particularly cognitive stress management as part of multimodal stress training requires self-awareness and self-reflection. This raises the question as to what extent such training corresponds to the cultural norms and values of East Asian seafarers [40]. An important feature of this population is, besides a stronger group orientation, the need to control emotions and save face in the communication process [41]. In this context, training or instruction for shortterm relaxation, such as power napping, would therefore be preferred, especially by the Asian crew members. Since the training of East Asian or East European seafarers takes place in their home countries, it is the responsibility of the crewing agencies or the maritime training centres there and - as a limitation of the present survey - cannot be evaluated in this study.

In view of the often described fatigue problem among seafarers due to the high mental and psychophysical stress on board [11, 42], special anti-fatigue training for nautical officers is recommended. This is already an integral part of compulsory training for pilots in Germany. The contents of such training should be: causes and symptoms of fatigue, sleep hygiene, principles of sleep and regulations for adherence of necessary rest and sleeping times. Furthermore, the high stress level of officers in the context of ship command highlights the need to develop and carry out "Multimodal Stress Management Training".

\section{CONCLUSIONS}

The present study clearly demonstrates the high stress level for ship's officers during the ship's operation, irrespective of their age. Cultural differences were found in the assessment of the general working and social life situation on board. Here, significantly more Asian crew members rated their work and social life situation as stressful compared to European seafarers. Also in light of the currently insufficient education in human resources management, it seems necessary to prepare the prospective ship's officers in maritime training centres for the special stress situations of ship operation. They should also enable them to recognise and take into account cultural differences in the stress perception and needs of subordinate crew members. "Multimodal Stress Management Training" and maritime "Diversity Training" are proposed for this purpose.

Especially for the East Asian, family-oriented crew members with a longer stay on board, the communication with the family is helpful against feelings of isolation and depressive moods. Visiting welfare facilities such as the Seamen's
Mission can also have positive effects on feelings of isolation and depression. It enables a change from the narrow, one-sided professional role on board to a different social environment in which no demands are made, uncomplicated contact is possible and the seaman finds understanding.

\section{FUNDING}

This study was funded by the Berufsgenossenschaft für Transport und Verkehrswirtschaft ("BG Verkehr"), Hamburg, Germany.

\section{ACKNOWLEDGEMENTS}

The authors would like to thank the seafarers and the shipping companies for taking part in this study. We also thank all interview partners of the maritime schools for their valuable comments. Many thanks are also owed to J. Hedtmann, C. Felten and B. Neubauer from the BG Verkehr for their support and the funding.

\section{INFORMED CONSENT}

Taking part in this study was voluntarily. All participants gave their informed consent before taking part in this study.

\section{CONFLICT OF INTEREST}

There are no conflicts of interest.

\section{REFERENCES}

1. Salomon K. Mental stress. Encyclopedia of Behavioral Medicine. https:// doi.org/10.1007/978-1-4419-1005-9_261(Last accessed on March).

2. Vincent V. Physical strain in the workplace. Labor Employment. 2011.

3. Forsell K, Eriksson $\mathrm{H}$, Järvholm B, et al. Work environment and safety climate in the Swedish merchant fleet. Int Arch Occup Environ Health. 2017; 90(2): 161-168, doi: 10.1007/s00420-016-1180-0, indexed in Pubmed: 27815725.

4. Nielsen MB, Bergheim K, Eid J. Relationships between work environment factors and workers' well-being in the maritime industry. Int Marit Health. 2013; 64(2): 80-88, indexed in Pubmed: 23788224.

5. Iversen RTB. The mental health of seafarers. Int Marit Health. 2012; 63(2): 78-89, indexed in Pubmed: 22972547.

6. Hystad SW, Eid J. Sleep and fatigue among seafarers: the role of environmental stressors, duration at sea and psychological capital. Saf Health Work. 2016; 7(4): 363-371, doi: 10.1016/j. shaw.2016.05.006, indexed in Pubmed: 27924241.

7. Carotenuto A, Molino I, Fasanaro AM, et al. Psychological stress in seafarers: a review. Int Marit Health. 2012; 63(4): 188-194, indexed in Pubmed: 24595974.

8. Oldenburg M, Baur X, Schlaich C. Occupational risks and challenges of seafaring. J Occup Health. 2010; 52(5): 249-256, doi: 10.1539/ joh.k10004, indexed in Pubmed: 20661002.

9. Oldenburg $\mathrm{M}$, Jensen $\mathrm{HJ}$, Wegner R. Burnout syndrome in seafarers in the merchant marine service. Int Arch Occup Environ Health. 2013; 86(4): 407-416, doi: 10.1007/s00420-012-0771-7, indexed in Pubmed: 22526089.

10. Rengamani J, Murugan MSA. study on the factors influencing the seafarers' stress. AMET Intern J Manag. 2012: 44.

11. Lundh M, Rydstedt LW. A static organization in a dynamic context: A qualitative study of changes in working conditions for Swedish 
engine officers. Appl Ergon. 2016; 55: 1-7, doi: 10.1016/j.apergo.2016.01.006, indexed in Pubmed: 26995030.

12. Jeżewska M, Leszczyńska I, Jaremin B. Work-related stress at sea self estimation by maritime students and officers. Int Marit Health. 2006; 57(1-4): 66-75, indexed in Pubmed: 17312695.

13. ISM. ISM Code (International Safety Management Code) of the International Maritime Organization, IMO 2018. http://www.imo.org/ en/OurWork/HumanElement/TrainingCertification/Pages/Default. aspx (Last accessed on March).

14. STCW. International Convention on Standards of Training, Certification and Watchkeeping for Seafarers. 1995. http://www.imo. org/en/OurWork/humanelement/trainingcertification/pages/ stcw-convention.aspx (Last accessed on March).

15. Progoulaki M, Roe M. Dealing with multicultural human resources in a socially responsible manner: a focus on the maritime industry. WMU J Marit Affairs. 2011; 10(1): 7-23, doi: 10.1007/s13437011-0003-0.

16. Sampson $\mathrm{H}$, Thomas M. The social isolation of seafarers: causes, effects, and remedies. Int Marit Health. 2003; 54(1-4): 58-67, indexed in Pubmed: 14974778.

17. Lu CS, Lai Kh, Lun YH, et al. Effects of national culture on human failures in container shipping: the moderating role of Confucian dynamism. Accid Anal Prev. 2012; 49: 457-469, doi: 10.1016/j. aap.2012.03.018, indexed in Pubmed: 22578904.

18. Jensen $\mathrm{OC}, \mathrm{S}$ rensen JFL, Thomas $\mathrm{M}$, et al. Working conditions in international seafaring. Occup Med (Lond). 2006; 56(6): 393-397, doi: $10.1093 /$ occmed/kql038, indexed in Pubmed: 16804089.

19. Lu CS, Hsu CN, Lee CH. The Impact of Seafarers' Perceptions of National Culture and Leadership on Safety Attitude and Safety Behavior in Dry Bulk Shipping. Int J e-Navigation Marit Econ. 2016; 4: 75-87, doi: 10.1016/j.enavi.2016.06.007.

20. Youssuf $\mathrm{S}$. The rationale of the workplace issues of a stress management event; an approach to address this issue in organisations and on-board. Int J Business and General Management. 2015; 4(4).

21. Leszczyńska I, Jeżewska M, Jaremin B. Work-related stress at sea. Possibilities of research and measures of stress. Int Marit Health. 2008; 59(1-4): 93-102, indexed in Pubmed: 19227742.

22. Adhabi E, Anozie C. Literature review for the type of interview in qualitative research. Int J Edu. 2017; 9(3): 86, doi: 10.5296/ije. v9i3.11483.

23. Grath $\mathrm{CM}$, Palmgren PJ, Liljedahl M. Interview: a research instrument for social science researchers. Int J Social Sciences, Humanities and Education 2017. https://www.tandfonline.com/doi/full/10.1080/ 0142159X.2018.1497149 (Last accessed on March).

24. Oltmann SM. Qualitative interviews: a methodological discussion of the interviewer and respondent contexts forum. Qualitative Social Res. 2016; 17(2): 15.

25. Kvale S, Brinkmann S. InterViews: learning the craft of qualitative research interviewing. Sage Publications Ltd., Los Angeles, London 2008.

26. McKay S. Filipino Sea Men: Constructing Masculinities in an Ethnic Labour Niche. J Ethnic Migration Studies. 2007; 33(4): 617-633, doi: 10.1080/13691830701265461.

27. Hinton DE, Lewis-Fernández R. Idioms of distress among trauma survivors: subtypes and clinical utility. Cult Med Psychiatry. 2010; 34(2): 209-218, doi: 10.1007/s11013-010-9175-x, indexed in Pubmed: 20407812.
28. Jensen HJ. Interkulturelle Verhaltensmuster und schifffahrtsspezifische Belastungen. Maritime Medizin. Ottomann C, Seidenstücker KH. Springer-Verlag, Berlin Heidelberg 2015: 127-132.

29. Sampson H, Ellis N. Seafarers' mental health and wellbeing. Seafarers International Research Centre 2019, Cardiff.

30. Appannah A, Meyer C, Ogrin R, et al. Diversity training for the community aged care workers: A conceptual framework for evaluation. Eval Program Plann. 2017; 63: 74-81, doi: 10.1016/j.evalprogplan.2017.03.007, indexed in Pubmed: 28431301.

31. Phillips BN, Deiches J, Morrison B, et al. Disability diversity training in the workplace: systematic review and future directions. J Occup Rehabil. 2016; 26(3): 264-275, doi: 10.1007/s10926-015-9612-3, indexed in Pubmed: 26519035.

32. Theotokas I, Progoulaki M, lakovaki H. Management of cultural diversity: identifying the training needs of seafarers and shore-based personnel in the European maritime shipping industry. Intern Assoc Marit Econ. Annul conference at Marseille 2013, France.

33. Daly A, Carey RN, Darcey E, et al. Using three cross-sectional surveys to compare workplace psychosocial stressors and associated mental health status in six migrant groups working in Australia compared with Australian-born workers. Int J Environ Res Public Health. 2019; 16(5): 735, doi: 10.3390/ijerph16050735, indexed in Pubmed: 30823505.

34. Smith LH, Hviid K, Frydendall KB, et al. Improving the psychosocial work environment at multi-ethnic workplaces: a multi-component intervention strategy in the cleaning industry. Int J Environ Res Public Health. 2013; 10(10): 4996-5010, doi: 10.3390/ijerph10104996, indexed in Pubmed: 24129115.

35. Kröll C, Doebler P, Nüesch S. Meta-analytic evidence of the effectiveness of stress management at work. Eur J Work Organizational Psychology. 2017; 26(5): 677-693, doi: 10.1080/1359432x.2017.1347157.

36. Boysen E, Schiller B, Mörtl K, et al. Preliminary analyses showed short-term mental health improvements after a single-day manager training. Int J Environ Res Public Health. 2018; 15(1): 108, doi: 10.3390/ijerph15010108, indexed in Pubmed: 29320444.

37. Palmer S. Multimodal relaxation method applied to counselling, psychotherapy and coaching. Euro J Couns Theory, Res Practice. 2017; 1 : 5.

38. Lehrer PM, Woolfolk RL, Wesley Sime E. (eds.). Principles and practice of stress management. Guilford Publications 2007.

39. Umanodan R, Kobayashi Y, Nakamura M, et al. Effects of a worksite stress management training program with six short-hour sessions: a controlled trial among Japanese employees. J Occup Health. 2009; 51(4): 294-302, doi: 10.1539/joh.18055, indexed in Pubmed: 19483369.

40. Carter T, Jepsen JR. Exposures and health effects at sea: report on the NIVA course: maritime occupational medicine, exposures and health effects at Sea Elsinore, Denmark, May 2014. Int Marit Health. 2014; 65(3): 114-121, doi: 10.5603/IMH.2014.0024, indexed in Pubmed: 25471159.

41. Wang YQ, Gu P. Reducing intercultural communication barriers between seafarers with different cultural backgrounds. International Association of Maritime Universities 2014. http://iamu-edu.org/wp-content/ uploads/2014/2007/ s2013-wang.pdf (Last accessed on March).

42. Raby M, Lee JD. Fatigue and workload in the maritime industry. Stress, workload and fatigue. Hancock PA, Desmond PA. Lawrence, Mahwah New Jersey 2001: 566-578. 